\title{
A ÁREA SOCIAL E A PRODUÇÃO DA REVISTA CHILENA DE TERAPIA OCUPACIONAL: REFLEXÕES A PARTIR TERAPIA OCUPACIONAL SOCIAL
}

\author{
EL ÁREA SOCIAL Y LA PRODUCCIÓN DE LA REVISTA \\ CHILENA DE TERAPIA OCUPACIONAL: REFLEXIONES \\ DESDE LA TERAPIA OCUPACIONAL SOCIAL
}

\author{
THE SOCIAL AREA AND CHILE OCCUPATIONAL THERAPY JOURNAL PRODUCTION: \\ REFLECTIONS FROM BRAZILIAN SOCIAL OCCUPATIONAL THERAPY
}

\section{Pamela Cristina Bianchi'; Ana Paula Serrata Malfitano ${ }^{2}$}

\begin{abstract}
Resumo
Introdução: O contexto de desigualdade social em consonância às políticas sociais e às discussões acerca do acesso à cidadania propôs para a Terapia Ocupacional a entrada em uma nova área: o social. A terapia ocupacional social brasileira prevê um recorte metodológico específico com ações para públicos que têm a vulnerabilidade social como eixo de sua demanda. Lançando mão dos pressupostos da terapia ocupacional social brasileira, investigou-se a produção da Revista Chilena de Terapia Ocupacional, com vistas a identificar a presença de textos sobre a área social. Método: Realizou-se um levantamento em dois momentos: catalogação de todos os textos publicados; seleção e análise dos artigos que remetiam direta ou indiretamente à área social. Resultados e Discussão: Foram publicados 182 artigos de 2001 a 2014, sendo descritos suas áreas, subáreas e países dos autores. Na segunda fase foram selecionados 19 textos relacionados ao campo social. A classificação dos trabalhos foi realizada em discussões no âmbito individual (07 textos) e em uma perspectiva coletiva (12 textos). Debate-se o desafio da área em avançar de uma perspectiva individual para o desenvolvimento de uma prática coletiva e social. Conclusão: A terapia ocupacional latino-americana deve desenvolver metodologias e aportes teóricos que sejam singulares à realidade da região e se direcionem a buscar respostas às demandas da sociedade. Propomos uma maior aproximação entre os países da região para a construção de uma perspectiva em terapia ocupacional comprometida socialmente com contexto latino-americano.
\end{abstract}

\section{Palavras-chave:}

Terapia Ocupacional; Vulnerabilidade Social; Terapia Ocupacional Social; Produção científica.

1 Mestranda em Terapia Ocupacional pelo Programa de Pós-graduação em Terapia Ocupacional - UFSCar. Especialista em Saúde da Família e Comunidade pela modalidade Residência - UFSCar, São Carlos, SP, Brasil. Laboratório METUIA, Departamento de Terapia Ocupacional, Universidade Federal de São Carlos, Rod. Washington Luís, Km 235, SP-310, CEP 13565-905, São Carlos, SP, Brasil, e-mail: pamelacbianchi@ gmail.com

2 Pós-doutora em Ciência Ocupacional pela Faculdade de Terapia Ocupacional da Western University Ontario, Canadá. Professora Adjunta do Departamento de Terapia Ocupacional e do Programa de Pós-graduação em Terapia Ocupacional, Universidade Federal de São Carlos - UFSCar, São Carlos, SP, Brasil. Laboratório METUIA, Departamento de Terapia Ocupacional, Universidade Federal de São Carlos, Rod. Washington Luís, Km 235, SP-310, CEP 13565-905, São Carlos, SP, Brasil, e-mail: anamalfitano@ufscar.br 


\title{
Resumen
}

Introducción: El contexto de desigualdad social en consonancia con las políticas sociales y las discusiones acerca del acceso a la ciudadanía propuso para la Terapia Ocupacional la entrada en una nueva área: lo social. La terapia ocupacional social brasileña proporciona un recorte metodológico específico con acciones para públicos que tengan la vulnerabilidad social como eje de su demanda. Utilizándose de los presupuestos de la terapia ocupacional social brasileña, se he investigado la producción de la Revista Chilena de Terapia Ocupacional, con vistas a identificar la presencia de textos acerca de la área social. Método: Se realizó una encuesta en dos etapas: colección de todos los textos publicados y selección y análisis de los artículos que hacían referencia directa o indirectamente con el ámbito social. Resultados y discusión: Fueron publicados 182 artículos desde 2001 hasta 2014, y se describen sus áreas, sub-áreas y países de los autores. En la segunda fase se seleccionaron 19 textos relacionados en la área social. La clasificación de los trabajos fue realizada de la siguiente manera: discusiones en un enfoque en el nivel individual (07 textos) y en una perspectiva colectiva (12 textos). El debate es el desafío en avanzar de una perspectiva individual al desarrollo de una práctica colectiva y social. Conclusión: La Terapia Ocupacional en Latinoamérica debe desarrollar metodologías y aportaciones teóricas que son singulares a nuestra realidad y dirigir la búsqueda de respuestas a las demandas de la sociedad. Proponemos vínculos más estrechos entre los países de la región para construir una perspectiva en terapia ocupacional socialmente comprometido con nuestro contexto.

\section{Palabras-clave:}

Terapia Ocupacional; Vulnerabilidad Social; Terapia Ocupacional Social; Producción científica.

Fecha de recepción: 02/09/2015

Fecha aceptación: 28/10/2016

\begin{abstract}
Introduction: The context regarding to the social inequality in agreement to the social policies, and the discussions about the citizenship proposed to the Occupational Therapy a new field of study: the social area. The Social Brazilian Occupational Therapy forecasts a specific methodological record to people who have their demand as the social vulnerability. Employing the assumptions of the Social Brazilian Occupational Therapy, we have used the Revista Chilena de Terapia Ocupacional in order to identify scientific reports about the social area. Method: The data collection was made in two moments. The first moment was the cataloging of all published texts, and the second one was the analysis of the scientific papers which referred either directly or indirectly to the social area. Results and Discussion: 182 scientific papers were published from 2001 to 2014, which described the Authors' areas, subareas and countries. On the second part 19 scientific papers were selected to the social field. These papers were classified according to the observation of the focus on the individual level (07 papers) and collective discussions (12 papers). The challenge of advance on the individual perspective to the development of collective and social practices has been discussed. Conclusion: The Latin-American Occupational Therapy has to develop methodologies and theoretical contributions which are exclusive to our reality, and are directed to find solutions to the society issues. We have proposed a higher approximation between the countries of the Latin America region in order to build a solid perspective of the Occupational Therapy in our social context.
\end{abstract}

\section{Keywords:}

Occupational Therapy; Social vulnerability; Social Occupational Therapy; Scientific production.

\section{INTRODUÇÃO}

No Brasil, a institucionalização da terapia ocupacional como profissão teve em seu percurso dois processos subjacentes. Um deles ocorreu em meados do século $X X$, no Rio de Janeiro, por meio do uso das ocupações como tratamento terapêutico no campo da saúde mental, guiados pelas ações da Dra. Nise da Silveira, assim como pelo tratamento moral; e posteriormente com a criação da Escola de Reabilitação do Rio de Janeiro. O outro processo ocorreu em São Paulo, na mesma época, sob o viés da reabilitação física, com a implantação do Instituto Nacional de Reabilitação e a criação de cursos para a formação de profissionais da área de rea- bilitação, dentre eles, o terapeuta ocupacional (Soares, 1991; De Carlo, Bartalotti, 2001).

A profissão ganha reconhecimento jurídico no país em 1969, voltada ao trabalho no campo da saúde em áreas "tradicionais" de intervenção: a saúde mental e a reabilitação física. A partir da década de 1970, os terapeutas ocupacionais brasileiros passaram a se defrontar com novas possibilidades no mercado de trabalho como a atuação em presídios, em asilos para idosos, em programas comunitários para crianças e adolescentes de baixa renda (Galheigo, 2003). 
Devido à ausência de metodologias, objetivos e bases teóricas para a constituição de um novo campo de ação, a prática se deu por meio do reconhecimento da demanda e da reprodução dos modelos de ação com os quais já estava familiarizada, basicamente numa perspectiva biomédica em uma clínica individualizada (Galheigo, 2003). Segundo Barros, Ghirardi e Lopes (2002), naquele momento a área social era compreendida como um contexto global, no qual não se abordava suas especificidades técnico-metodológicas, "tratava-se de um social substantivado, esvaziado de historicidade e de sua força explicativa do movimento e do real" (p. 98), ou seja, diluído entre as demais perspectivas de atuação.

As décadas de 1970 e 1980 trouxeram uma nova perspectiva acerca do conceito de cidadania por meio de movimentos sociais e reivindicações em busca da democracia e de reformas políticas e sociais para o Brasil, tendo reflexos também na atuação do terapeuta ocupacional. Os anos 1990, em consequência, foram marcados pela construção da nova Constituição Federal e por novas perspectivas de atuação política, juntamente com a vivência de um contexto econômico neoliberal. Para a terapia ocupacional as práticas destinadas à área social se ampliavam em consonância às novas políticas públicas e sociais, em um contexto de desigualdade social e implementação de políticas neoliberais, juntamente às discussões acerca do acesso à cidadania, tendo destaque: a Lei Orgânica da Assistência Social, a Lei Orgânica da Saúde e o Estatuto da Criança e do Adolescente (Galheigo, 2003).

Além disso, nas áreas de maior tradição do trabaIho do terapeuta ocupacional, a perspectiva territorial e os processos de desinstitucionalização advindos com as reformas psiquiátrica e sanitária ${ }^{3}$ possibilitaram o desenvolvimento de novas bases para a atuação pro-

\footnotetext{
No Brasil, as reformas psiquiátrica e sanitária se constituíram como movimentos políticos, impregnados de ética e ideologias, a partir de um processo de construção de luta popular pela transformação da sociedade, nas décadas de 1970 e 1980. A Reforma Sanitária trouxe a discussão da saúde como direito universal de todos os cidadãos brasileiros, mudando substancialmente o acesso aos serviços e o princípio jurídico estabelecido até então. A Reforma Psiquiátrica questionou a ordem da institucionalização e exclusão daquela população, na luta pelos seus direitos. Ambos os movimentos impulsionaram a mudança constitucional brasileira de 1988 e a decorrente criação do Sistema Único de Saúde, SUS, o qual estabelece que a saúde é direito de todos e dever do Estado (Yasui, 2006; Brasil, 1990).
}

fissional, calcadas no sujeito de direitos, no território, na atividade como instrumento de inserção no universo de trabalho e emancipação econômica e no terapeuta ocupacional como um ator político e social (Barros et al., 2002).

Na ótica brasileira, a constituição de uma área denominada social na terapia ocupacional deu-se pela discussão acerca do acesso aos direitos e do fortalecimento das redes sociais de suporte (Castel, 1994) para o grupo com o qual se trabalha. Para tanto, propôs o desenlace da mediação saúde-doença, a partir do extravasamento do campo da saúde e o confronto concreto com as realidades sociais (Barros et al. 2002). A ação da terapia ocupacional na área social prevê um recorte metodológico específico para o qual se voltam ações para públicos que têm a vulnerabilidade social, a marginalização e a ruptura das redes sociais de suporte como eixo central de sua demanda de atenção (Barros et al., 2002).

Os primeiros desenhos teórico-metodológicos sistematizados na terapia ocupacional social brasileira tiveram como base as reflexões sobre questão social e vulnerabilidade social desenvolvidas pelo sociólogo francês Robert Castel (1998). Segundo o autor, a sociedade contemporânea tem sido marcada pela constituição de grupos formados por sujeitos que se encontram alheios às relações econômico-sociais, oriundos da aliança de um duplo processo de desligamento: da relação com o trabalho e da inserção social e relacional (Castel, 1994). O recorte desses dois eixos circunscreve três zonas distintas do espaço social: zona de integração - designa garantias de um trabalho estável e mobilização de suportes relacionais sólidos; zona de vulnerabilidade associa precariedade do trabalho e fragilidade relacional; e zona de desfiliação - implica em ausência de trabalho e isolamento social. Ainda há a constituição de uma quarta zona - a zona de assistência - que se configura a partir de diferentes ações de assistência a tais grupos. Para o sociólogo, altos índices de vulnerabilidade social alimentam a zona de desfiliação, uma vez que tais zonas são porosas e pode haver, portanto, a circulação dos sujeitos entre elas (Castel, 1994).

A área de Terapia Ocupacional Social no Brasil vem ganhando institucionalidade pelo seu desenvolvimento como campo de ensino de graduação (Pan, Lopes, 2013), desenvolvimento de pesquisas (Lopes, Borba, Silva, Malfitano, 2012) e reconhecimento profissional, tendo sido normatizada como especialidade, em 2010, por meio de resolução específica do Conselho Federal de Fisioterapia e Terapia Ocupacional (Coffito, 2010). 
No âmbito latino-americano, a atuação da terapia ocupacional com a questão social "têm ganhado visibilidade e destaque no cenário profissional, demonstrando uma ascendência da área e um número maior de possibilidades de intervenção" (Lopes et al., 2012a, p.30). Abre-se o questionamento sobre como os demais países da América Latina vêm desenvolvendo as interfaces entre a questão social contemporânea e a terapia ocupacional.

Para contribuir com essa discussão, a presente investigação debruçou-se sobre as produções divulgadas na Revista Chilena de Terapia Ocupacional, visto que se trata de um periódico de reconhecimento na América Latina, indexado em bases internacionais e importantes para divulgação de produções ${ }^{4}$. Como assinala Moreno (2012), o periódico tem o mundo virtual como aliado e encontra-se com todos os seus volumes com acesso livre pela rede mundial de computadores, o que facilita a busca à sua produção pelos terapeutas ocupacionais latino-americanos.

Assim, lançando mão dos pressupostos teórico metodológicos da terapia ocupacional social brasileira, investigou-se a produção divulgada no periódico chileno, com vistas a identificar os textos publicados sobre práticas e discussões que abordem a dimensão social.

\section{Procedimentos Metodológicos}

Realizou-se um levantamento bibliográfico acerca das produções atuais dos terapeutas ocupacionais latino-americanos em dois momentos subsequentes: o primeiro consistiu em uma imersão em todo o universo da revista e sua catalogação, em organização própria das autoras; e o segundo se deu pela seleção e análise dos artigos que remetiam direta ou indiretamente à questão social.

4 A Revista Chilena de Terapia Ocupacional teve início em 2001 sob organização da Escuela de Terapia Ocupacional de la Facultad de Medicina de la Universidad de Chile. Segundo sua missão divulgada, tem como objetivo publicar trabalhos originais sobre temas de interesse da Terapia Ocupacional e da Ciência Ocupacional. A revista tem indexação nas bases de dados: LILACS, BIREME e LATINDEX, desde o ano de 2008. Possui atualmente catorze volumes, dos quais dez se organizaram em publicações anuais e os últimos quatro em publicações semestrais. O corpo editorial da revista é formado por editores, coeditores, editor de composição e corretor, todos compostos por profissionais da Universidad de Chile.
Desta forma, a primeira etapa consistiu em uma catalogação de todos os artigos disponíveis na Revista Chilena de Terapia Ocupacional em um banco de dados no

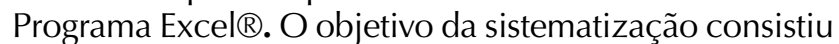
em reunir todo o universo de textos do periódico para possibilitar a visualização do seu conjunto e traçar reflexões sobre as áreas e subáreas mais estudadas.

A fim de organizar a sistematização, foram elaboradas - em conjunto com parte da equipe do Laboratório METUIA/UFSCar do Departamento de Terapia Ocupacional da Universidade Federal de São Carlos, São Paulo, Brasil ${ }^{5}$ - categorias de descrição dos textos. As categorias foram estabelecidas de acordo com informações evidenciadas, tais como: título, ano de publicação, meio de acesso (impresso e/ou online), nome dos autores, instituição e cidade/estado/país dos autores, resumo, área e subárea referentes ao texto e metodologia empregada.

O segundo momento teve como objetivo conhecer as discussões a respeito da questão social contemporânea presentes nos textos e seus reflexos na terapia ocupacional latino-americana. O referencial adotado de análise filia-se aos estudos teóricos da terapia ocupacional social no Brasil, buscando identificar chaves analíticas que se dediquem à compreensão de questões microssociais e suas inter-relações com o contexto macrossocial. Em outras palavras, parte-se de uma compreensão da necessária associação entre as dimensões pessoal e social para que, a partir de uma perspectiva coletiva, se possa falar de intervenções profissionais, como do terapeuta ocupacional, na complexa e múltipla contemporaneidade social (Barros et al., 2002).

A sistematização das publicações da Revista Chilena de Terapia Ocupacional elaborada, no primeiro momento, nos permitiu a identificação de temáticas e suas abordagens. A partir daí, tendo por base a pesquisa bibliográfica realizada por Reis (2008) acerca da produção científica da Terapia Ocupacional Social brasileira, foram adaptados os critérios de inclusão e exclusão.

Os critérios de inclusão abarcam: textos escritos e desenvolvidos por terapeutas ocupacionais em instituições latino-americanas, excetuando as brasileiras, como terceiro setor ou conveniadas das áreas de assistência social, da justiça, da educação e/ou da cultura; refle-

\footnotetext{
O Projeto METUIA é um grupo interinstitucional de estudos, formação e ações pela cidadania de crianças, adolescentes e adultos em processos de ruptura das redes sociais de suporte. Realiza atividades de ensino, pesquisa e extensão acadêmica na área de Terapia Ocupacional Social (Barros, Lopes, Galheigo, 2007).
} 
xões sobre a responsabilidade social, histórica e o papel ético-político dos terapeutas ocupacionais; e textos que discorressem sobre a ocupação, com enfoque na justiça ocupacional e/ou sua contextualização social.

Os critérios de exclusão foram: textos escritos somente por autores brasileiros e/ou não oriundos da região latino-americana; e textos que apresentassem abordagens clínicas ou centradas em questões envolvendo saúde-doença, tratamento e reabilitação.

Após a elaboração criteriosa dos elementos de seleção dos artigos, foi realizada a leitura dos títulos, resumos e palavras-chave, com vista a selecionar o maior número de artigos e resumos referentes à investigação. Em seguida, realizamos a leitura do trabalho completo, objetivando identificar no corpo do texto as temáticas de interesse da pesquisa e verificar sua aplicabilidade nos critérios acima apresentados.

\section{Resultados}

O levantamento inicial partiu da análise de 182 artigos publicados desde o início do periódico em 2001 até o ano de 2014. Observa-se um aumento significativo das publicações a partir do ano de 2011, quando os números dos volumes passam a ser publicados semestralmente. Destaca-se o ano de 2014 com dois números regulares e um monográfico especial (com o tema de deficiências), ampliando a quantidade de artigos publicada. Apresenta-se abaixo, no Gráfico 1, o número de artigos publicados por ano.

Número de artigos publicados na Revista Chilena de Terapia Ocupacional por ano.

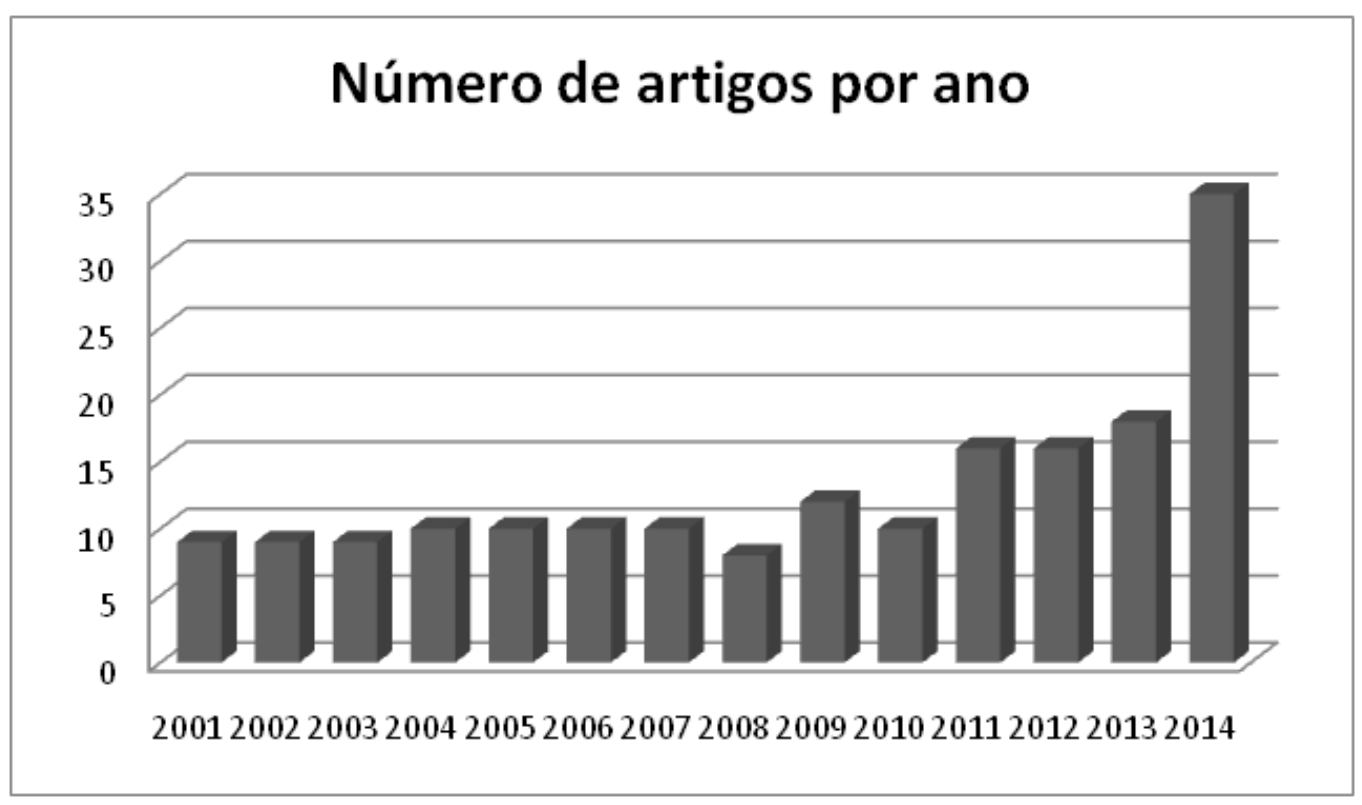

Em relação aos autores, buscou-se investigar as instituições com as quais se encontravam vinculados e os países de origem. Observamos, quanto às instituições, que o maior número de publicações (123) 68\% está ligada às universidades, apontando a academia como grande responsável pela produção científica da área, como esperado. Os demais trabalhos, principalmente àqueles vinculados aos hospitais, centros clínicos, escolas especiais e secretarias de saúde discorreram sobre práticas profissionais, somando $17 \%$ (31) dos textos analisados. Destaca-se que 15\% (28) do material não indicavam a instituição vinculada.

Sobre o país de origem, com vistas a identificar de onde as publicações eram, observamos que $77 \%$ (141) 
dos textos vinculavam-se a países latino-americanos, sendo eles: Argentina, Brasil, Colômbia, Chile, México, Paraguai, Peru, Uruguai e Venezuela. A maior parte dos trabalhos vem da produção chilena com 99 artigos (54\%); seguidos por autores argentinos, com 19 produções $(11 \%)$; pelos colegas colombianos e brasileiros, com oito (4\%) e sete, aproximadamente $4 \%$, respectivamente. A publicação espanhola na revista chilena atingiu seis artigos publicados $(3 \%)$, os colegas norte-americanos seguiram com duas contri- buições ( $1 \%)$, assim como os colegas venezuelanos, com o mesmo número; e com apenas um trabalho cada $(0,5 \%)$ encontram-se autores paraguaios, uruguaios, mexicanos e suecos. Ainda, há publicações oriundas de alianças internacionais, como Colômbia e Brasil, Suécia e Canadá e Suécia e Chile, todos com um artigo cada $(0,5 \%)$. Infelizmente, grande número de textos, $18 \%$ (32), não evidenciou este dado. O gráfico 2 apresenta a distribuição de países da produção da revista.

Países de procedência dos autores dos artigos publicados na Revista Chilena de Terapia Ocupacional.

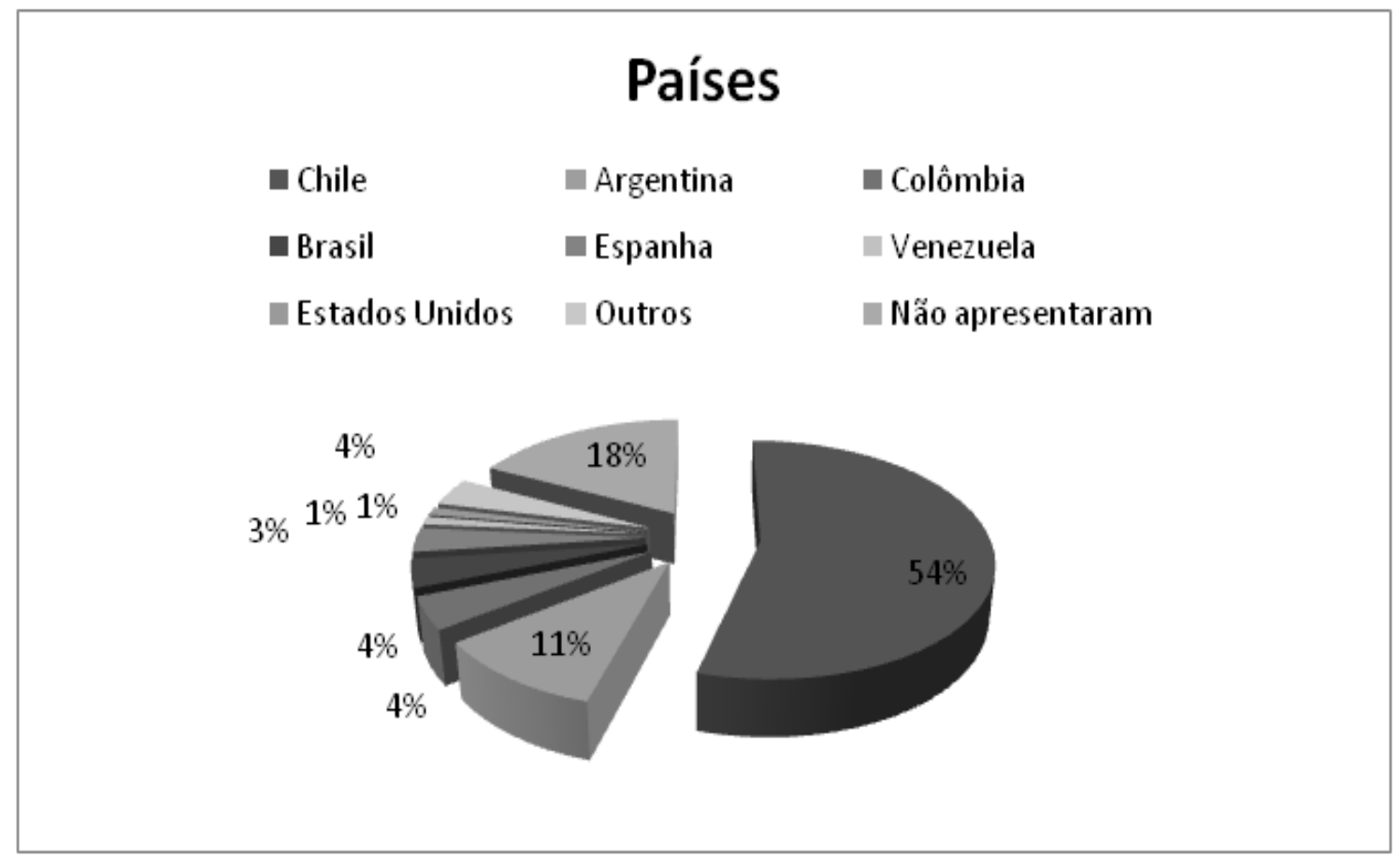

A partir da leitura e dos dados explicitados no título, resumo e palavras-chave, traçamos as categorias "área" e "subárea" do texto. Destaca-se que ao surgir a palavra "terapia ocupacional" ou algum correlato como "terapeuta ocupacional" em pelo menos um destes espaços, a área era definida como "Terapia Ocupacional". Caso este critério não fosse cumprido, a área era definida conforme outros três grandes grupos: "Ciências Humanas", "Ciência da Ocupação" e "Ciências da Saúde". Desta forma, obtivemos como resultado grande número de trabalhos referentes à área de terapia ocu- pacional, 63\% (115), conforme esperado. Em seguida, trabalhos voltados à área das "Ciências da Saúde", (45) 25\% do total. As áreas "Ciências Humanas" e "Ciência da Ocupação" tiveram 12 publicações (7\%) e 10 publicações $(5 \%)$, respectivamente. Notamos que a literatura latino-americana de terapia ocupacional encontrada na Revista Chilena de Terapia Ocupacional investe na produção de conhecimento referente à própria área de atuação, conforme anunciado em sua missão. O gráfico 3 apresenta a representação visual desta distribuição. 
Gráfico 3

Áreas de publicação dos artigos publicados na Revista Chilena de Terapia Ocupacional

\section{Áreas}

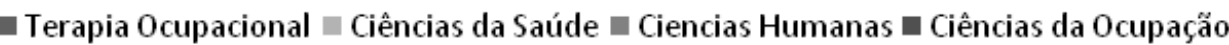

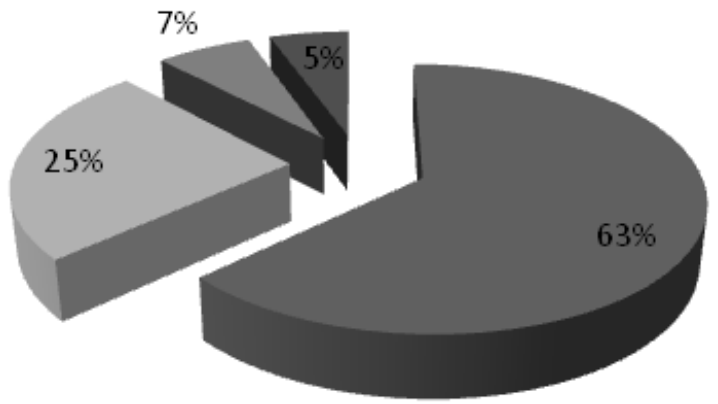

Lançamos luz à análise das "subáreas" discutidas nos textos, buscando apreender os enfoques utilizados pelos autores. A classificação das subáreas foi delinea- da a partir dos temas anunciados nos títulos, resumos e palavras-chave. Seguem os resultados apresentados na Tabela 1.

Tabela1

Subáreas de publicação apresentadas nos artigos publicados na Revista Chilena de Terapia Ocupacional.

\begin{tabular}{|c|c|c|}
\hline Subárea & Total de textos & Percentual \\
\hline Gerontologia & 21 & $11,5 \%$ \\
\hline Saúde Mental & 21 & $11,5 \%$ \\
\hline Rundamentos da Terapia Ocupacional & 17 & $9,5 \%$ \\
\hline Reabilitação Física & 16 & $9 \%$ \\
\hline Saúde do Trabalhador & 14 & $7,5 \%$ \\
\hline Ocupação & 14 & $7,5 \%$ \\
\hline Contexto Hospitalar & 12 & $6,5 \%$ \\
\hline Outras Deficiências & 11 & $6 \%$ \\
\hline Formação Acadêmica & 11 & $6 \%$ \\
\hline Desenvolvimento Humano & 9 & $5 \%$ \\
\hline Contexto Comunitário & 8 & $4,5 \%$ \\
\hline Educação & 7 & $4 \%$ \\
\hline Área social & 6 & $3 \%$ \\
\hline Deficiência Intelectual & 4 & $2 \%$ \\
\hline Drogas & 4 & $2 \%$ \\
\hline
\end{tabular}




\begin{tabular}{|c|c|c|}
\hline Saúde Pública & 2 & $1 \%$ \\
\hline Trabalho & 2 & $1 \%$ \\
\hline Cultura & 2 & $1 \%$ \\
\hline Cuidados Paliativos & 1 & $0,5 \%$ \\
\hline TOTAL & 182 & $100 \%$ \\
\hline
\end{tabular}

Podemos observar que os grupos de maior representatividade são respectivamente: "Gerontologia", "Saúde mental", "Fundamentos da Terapia Ocupacional", "Reabilitação física", "Saúde do trabalhador" e "Ocupação" - demonstrando uma produção de conhecimento voltada aos campos de atuação que, é possível inferir, o terapeuta ocupacional mantém sua maior inserção na academia e na prática profissional.

Na categorização referente à metodologia empregada nos estudos, nos preocupamos em sistematizar apenas se a pesquisa era "qualitativa", "quantitativa" ou "qualitativa e quantitativa", sem lançar foco aos métodos aplicados. Dos trabalhos analisados, 31\% do total (56), utilizavam-se de análise qualitativa, 7\% (13) do total de análise quantitativa e $5 \%$ (9) utilizavam a análise combinada, ou seja, eram qualitativos e quantitativos. Entretanto, a maioria dos resumos, 57\% (104), não continha a informação sobre a metodologia adotada.

A sistematização favoreceu uma visualização panorâmica da produção de conhecimento da terapia ocupacional latino-americana. Os dados foram observados de um âmbito geral e pouco detalhados, mas, ainda sim, possibilitaram-nos apreender algumas de suas singularidades. Destacam-se as discussões a respeito das ocupações e a forte vinculação com a Ciência da Ocupação, o que se constitui como pontos distintos do embasamento teóricometodológico da produção em terapia ocupacional no Brasil (Galheigo, Simó Algado, 2012). Por outro lado, também surgem congruências em outros campos, como o alto investimento das produções em áreas "tradicionais" como a reabilitação física e a saúde mental (Soares, 1991).

$\mathrm{Na}$ segunda etapa foram aplicados os critérios de inclusão e exclusão na busca de textos que denominamos da área social.

Foram selecionados 19 artigos, $10 \%$ do universo total de textos do periódico. Os trabalhos escolhidos foram publicados no período entre os anos 2003 e 2014, nos quais é possível observar certa linearidade quanto às produções, com destaque para o ano de 2008, quando, com oito artigos no total publicados, três $(40 \%)$ versam sobre a área social. O gráfico 4 apresenta a comparação entre total de artigos publicados no ano e aqueles selecionados.

Gráfico 4

Publicações sobre a área social na Revista Chilena de Terapia Ocupacional.

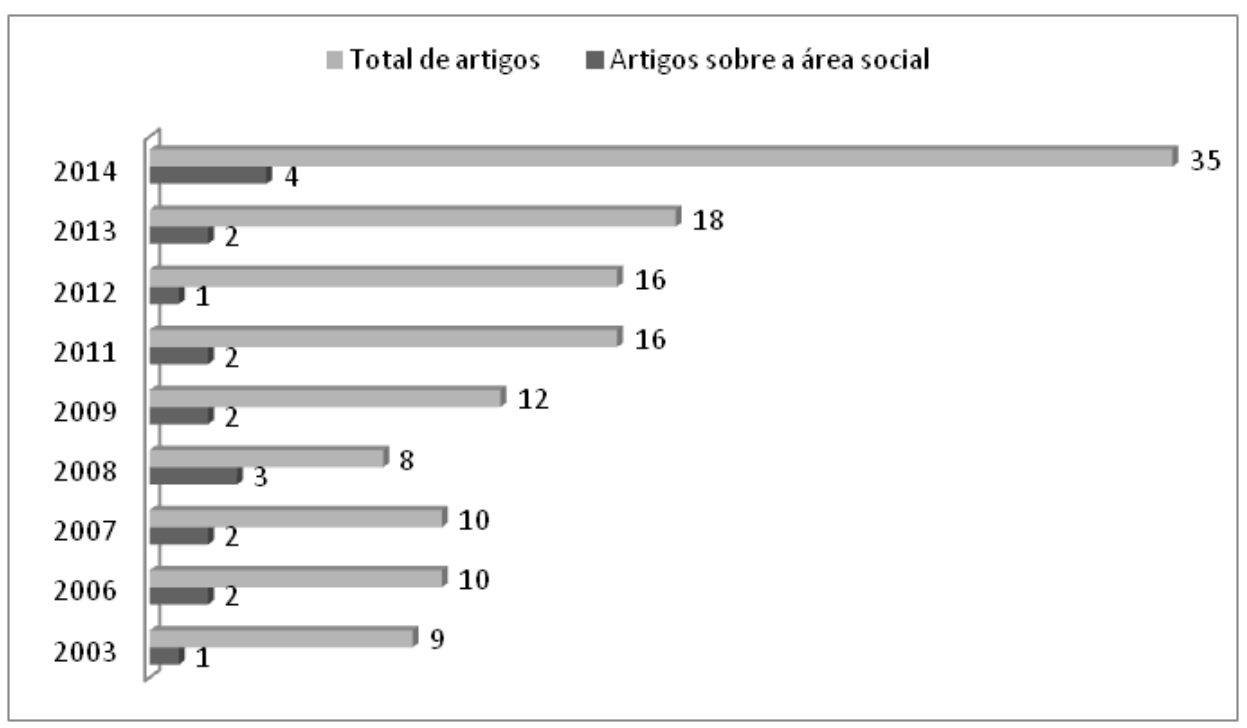


A Tabela 2 descreve os trabalhos selecionados e utilizados para análise identificados como do campo social.

Tabela 2

Listagem completa dos artigos referentes à área social publicados na Revista Chilena de Terapia Ocupacional

\begin{tabular}{|c|c|c|}
\hline Título do Texto & Autor & Ano \\
\hline Aproximación crítica a la terapia ocupacional en la era de la información & Felizzola & 2003 \\
\hline $\begin{array}{l}\text { Informe de primera etapa del proyecto de investigación sobre el tema "La modifica- } \\
\text { ción de los hábitos y rutinas diarias de personas afectadas por la catástrofe hídrica de } \\
\text { la ciudad de Santa Fe" }\end{array}$ & Boggio et al. & 2006 \\
\hline Un enfoque sobre la medición y nuestra disciplina & Capozzo; Mengelberg & 2006 \\
\hline $\begin{array}{l}\text { Definición y desarrollo del concepto de Ocupación: ensayo sobre la experiencia de } \\
\text { construcción teórica desde una identidad local. }\end{array}$ & Alvarez et al. & 2007 \\
\hline La formación de terapeutas ocupacionales desde un interés crítico de la Educación & Muñoz Espinosa & 2007 \\
\hline $\begin{array}{l}\text { OCUPARSE: Una propuesta de intervención con personas privadas de libertad basado } \\
\text { en la ocupación }\end{array}$ & Díaz et al. & 2008 \\
\hline $\begin{array}{l}\text { "Significados Asociados a la Actividad Delictiva". En hombres que se encuentran pri- } \\
\text { vados de libertad, por delito de robo, en Centro de Detención Preventiva Santiago Sur. }\end{array}$ & Drápela et al. & 2008 \\
\hline Talleres de promoción de resiliencia para adolescentes en alto riesgo social. & Arellano; Correa & 2008 \\
\hline $\begin{array}{l}\text { Hacia la construcción de las prácticas comunitarias de terapeutas ocupacionales en } \\
\text { Chile, desde una mirada socio histórica, desde } 1972 \text { hasta la actualidad. }\end{array}$ & Oyarzun et al. & 2009 \\
\hline Ocupación y literatura, un análisis desde la dialéctica materialista. & Ramírez; Schliebener & 2009 \\
\hline $\begin{array}{l}\text { La Filosofía de la Ocupación Humana y el Paradigma Social de la Ocupación. Algu- } \\
\text { nas reflexiones y propuestas sobre epistemologías actuales en Terapia Ocupacional y } \\
\text { Ciencias de la Ocupación. }\end{array}$ & Morrison et al. & 2011 \\
\hline $\begin{array}{l}\text { La retórica de la ciencia. Descripciones y reflexión crítica respecto a la conformación } \\
\text { del conocimiento. Aportes para la Terapia Ocupacional }\end{array}$ & Morrison & 2011 \\
\hline $\begin{array}{l}\text { Aportes para el debate sobre los inicios de la profesionalización de la terapia ocupa- } \\
\text { cional en Argentina }\end{array}$ & Testa & 2012 \\
\hline $\begin{array}{l}\text { Acercamientos teorico-éticos sobre la relación entre la terapia ocupacional y la cien- } \\
\text { cia: implicancias en las prácticas disciplinares. }\end{array}$ & Valderrama Nuñez & 2013 \\
\hline $\begin{array}{l}\text { Gubernamentalidad y biopolítica: una aproximación con los saberes y prácticas histó- } \\
\text { ricas de la terapia ocupacional en Chile. }\end{array}$ & $\begin{array}{l}\text { Herrera Sandoval; Val- } \\
\quad \text { derrama Núñez }\end{array}$ & 2013 \\
\hline Identificación delictual juvenil: una propuesta de intervención ocupacional & Poblete & 2014 \\
\hline $\begin{array}{l}\text { La contribución de la ocupación en la construcción de la cultura en la feria libre de la } \\
\text { comuna de Valdivia. }\end{array}$ & Muñoz et al. & 2014 \\
\hline La casa de los sueños: ocupación, actividad transgresora y construcción de identidad & Cifuentes et al. & 2014 \\
\hline Terapia ocupacional y andragogía. Un llamado a la inclusión desde el fin del mundo & Aranda et al. & 2014 \\
\hline
\end{tabular}




\section{DısCUSSÃO}

A América Latina, região das veias abertas, como intitula Eduardo Galeano (1982), tem sua constituição histórica marcada pela exploração europeia, durante a colonização, e anos mais tarde pelos norte-americanos, centralizadores do poder econômico atual. Segundo o escritor e jornalista uruguaio, as desigualdades econômicas, o grande número de desempregados, a alta inflação, a pobreza, o subdesenvolvimento e a vulnerabilidade social são resquícios da exploração desenfreada da terra e seus frutos, e dos homens e sua capacidade de trabalho (Galeano, 1982).

Neste cenário social marcado por explorações, desigualdades e vulnerabilidades sociais é indispensável um olhar sobre sua construção histórica e as consequentes demandas decorrentes desse processo. Faz-se necessário promover discussões e reflexões para a compreensão da realidade social, bem como criar metodologias de ação/intervenção e estratégias de enfrentamento, competindo aos profissionais envolvidos com a defesa dos direitos e a efetivação de políticas sociais, o fortalecimento de práticas que se dediquem a esse campo de ação, incluindo o terapeuta ocupacional (Lopes et al., 2012; Lopes, Adorno, Malfitano, Takeiti, Silva, Borba, 2008).

$\mathrm{Na}$ terapia ocupacional latino-americana, pósdécada de 1990, tem-se destacado a valoração dos coletivos e dos contextos. Desta maneira, a crítica à visão reducionista das problemáticas sociais e a busca da transformação social por meio da atuação profissional ganham destaque, alicerçados no compromisso ético -político dos profissionais (Galheigo, 2014).

Galheigo (2014) destaca que os terapeutas ocupacionais contemporâneos frente às tensões sociais dividem-se, não claramente, em dois movimentos. Há profissionais que realizam sua atuação a partir de uma concepção individualizada e abstrata da subjetividade, "adotando a perspectiva de que os problemas devem ser tratados como transtornos pessoais" (p. 219), calcada em modelos já existentes. Em contraposição há aqueles que baseiam sua prática em uma concepção coletiva de subjetividade, ou seja, voltada aos aspectos contextuais, sejam eles social, cultural, econômico, ecológico e/ou político.

Tendo como base os resultados encontrados no levantamento realizado, optou-se por lançar mão das reflexões de Galhiego (2014), dividindo os artigos selecionados em dois subgrupos, a saber: "a emergência da área social: descobertas e entraves a partir de uma nova atuação", com o objetivo de discutir a intervenção em terapia ocupacional a partir da prática profissional e os entraves advindos do enfoque em uma perspectiva individual, quando em interface com o cenário social; e "os caminhos da terapia ocupacional e seu enlace com o social", com vias a identificar os questionamentos discutidos na área social, buscando bases para uma prática alicerçada numa perspectiva macrossocial.

A emergência da área social: descobertas e entraves a partir de uma nova atuação

A área social, na terapia ocupacional brasileira, implica em uma leitura da realidade e da problemática expressa pela população assistida com vias a identificar, em um âmbito macro, sua origem. A população alvo da terapia ocupacional social vivencia um distanciamento do exercício de seus direitos fundamentais, como acesso à educação, saúde, habitação, segurança, cultura e ao lazer (Reis, Barros, Uchidomari, 2010).

Ao se confrontar com as problemáticas sociais, a questão da busca pela garantia de direitos se faz presente como um recurso de intervenção e/ou de uma mediação social. Observamos proximidade das discussões brasileiras com as discussões latino-americanas neste aspecto, especificamente acerca da promoção e da dificuldade de acesso aos direitos sociais.

Os relatos de experiências selecionados trouxeramnos a discussão acerca da garantia de direitos, como de moradia, àqueles que sofreram desastres ambientais, sendo relatado o caso da catástrofe hídrica vivenciada pela província de Santa Fé, na Argentina (Boggio et al., 2006). Outro artigo relata o direito à educação como busca de autonomia para idosos institucionalizados por meio da andragogia, a arte de ensinar adultos (Aranda; Yupanki; Verdugo; 2014). A discussão sobre a ausência e a busca de direitos sociais se fez presente nos artigos que abordaram a intervenção da terapia ocupacional com jovens e adultos que cometeram ato infracional, seja em internação em penitenciárias ou em regime residencial (Diáz, Encina, Sepúlveda, Gonzalo, 2008; Drápela, Huidobro, Núñez, Palacios, 2008; Poblete, 2014; Cifuentes, Molina, Moya, Palacios, 2014).

No Brasil, muitas discussões ocorreram com base no questionamento que indagava se o social seria uma área com objeto e método de atuação específicos ou se seria uma dimensão de toda intervenção em terapia ocupacional (Lopes, Malfitano, Silva, Borba, 2015). Debateu-se, principalmente na década de 1980, a insuficiência do modelo da área de saúde para o trabalho terapêutico-ocupacional na área social, na medida em que as intervenções requerem a criação de um corpo 
específico de conhecimento para embasar e justificar sua atuação (Barros et al., 2002).

Oito artigos, a maioria relatos de experiência, referem-se à prática na área social com base em pressupostos da Ciência Ocupacional e do campo da saúde, a partir de uma abordagem no indivíduo e calcada em modelos de atuação já existentes.

Quatro dos artigos selecionados (Diáz et al., 2008; Drápela et al., 2008; Poblete, 2014; Cifuentes et al., 2014) apresentam intervenções com população privada de liberdade e em todos há a abordagem ocupacional do indivíduo, como no texto "OCUPARSE: Una propuesta de intervención con personas privadas de liberdad basado en la ocupación", o qual trabalha sob a perspectiva da rotina ocupacional e de novas ocupações para a reinserção social de pessoas encarceradas (Diáz et al., 2008). O artigo desenvolvido por Poblete (2014) visualiza a atuação do terapeuta ocupacional como estratégia para promover a participação dos jovens em conflito com a lei em novas ocupações, modificando e adequando seu estilo de vida às novas preferências.

O conceito de ocupação, em um primeiro momento na profissão, foi definido como a "actividad com sentido em que la persona participa cotidianamente" (Alvarez et al., 2007, p.4). Nota-se que o próprio conceito remete a uma ação individualizada representando congruência entre as intervenções realizadas e o seu embasamento teórico. O que se discute é se o conceito de ocupação centrado no indivíduo responde às demandas do âmbito coletivo: pode-se tomar como alicerce de uma prática na área social, com problemáticas sociais, um conceito focalizado apenas em um sujeito individual? Quando as ocupações são vistas como aquelas realizadas por indivíduos, questiona-se se os trabalhos apresentados não deveriam as retratá-las sob uma perspectiva coletiva e macrossocial.

As abordagens e manejos de atuação, ligados ao campo da saúde e ao sujeito individual, apresentam uma maior indicação à terapia ocupacional voltada ao âmbito clínico, podendo-se inferir como uma resposta que estende sua atuação.

Pontua-se a necessidade de recontextualizar a terapia ocupacional para atuação na área social com metodologias e referenciais próprios, que atendam à demanda da população. A Terapia Ocupacional Social brasileira tem defendido o desenlace com o campo da saúde para que se possa desenvolver intervenções voltadas para o social, no desafio de uma contribuição terapêutico ocupacional para a discussão acerca dos processos de inserção social (Barros, Ghirardi, Lopes, 2007).
Esse debate é corroborado por outros autores. Segundo Navarrete Salas e colaboradores (2015), a terapia ocupacional latino-americana hoje está transitando para o plano sociocomunitário por meio da intervenção clínica, uma vez que a Atenção Primária à Saúde tem recuperado seu protagonismo por meio das novas políticas publicas de saúde. No entanto, a ida ao território extrapola os campos de atuação da saúde e a profissão deve operar também em outros campos, como a educação, a justiça, a gestão de políticas sociais. Os autores afirmam que os profissionais estão realizando grande esforço para sistematizar e desenvolver esta nova ação, desde a definição deste papel até uma maior preocupação com o compromisso do terapeuta ocupacional com as atuais mudanças sociais (Navarrete Salas et al., 2015).

\section{Os caminhos da terapia ocupacional e seu enlace com o social}

O caminho de uma profissão é reflexo do desempenho de suas funções sociais, de suas construções históricas e das práticas realizadas (Medeiros, 2003). Para a terapia ocupacional, a evolução histórica não pode ser isolada do conjunto de relações e dos valores ideológicos da formação social em que ela se inscreve, no interior de um sistema político e sociocultural de cada local (Cavalcante, Tavares, Bezerra, 2008).

$\mathrm{Na}$ terapia ocupacional social, o processo ocorre da mesma forma, as intervenções devem ser dimensionadas pela compreensão da demanda e seu enraizamento no interior das contradições sociais, requerendo uma compreensão dos processos históricos e socioculturais do território a ser adentrado (Barros et al., 2002, Barros, Ghirardi, Lopes, 2007).

Observamos que a produção latino-americana, em especial a chilena e a argentina, tem se debruçado e desenvolvido reflexões importantes acerca dos aspectos históricos em meio às sociedades que a terapia ocupacional foi construída.

Daniela Testa (2012) resgata a constituição sóciohistórica da América Latina: crescente urbanização e industrialização na década de 1950 e o alto índice de acidentes de trabalho, implementação dos sistemas de seguridade social e seus reflexos na prática, a emergência das epidemias de poliomielite e a discussão de gênero com a participação massiva de mulheres no início da profissão. Elabora a reflexão acerca do contexto social argentino e a institucionalização profissional. 
No âmbito chileno, Oyarzun, Zolezzi, Núñez e Palacios (2009) desenvolvem um trabalho com o objetivo de demonstrar a construção das práticas de terapia ocupacional que, a partir de diversas perspectivas, têm realizado intervenções no âmbito comunitário, com vias a entrelaçar seu desenvolvimento com os contextos históricos do país, em especial o período pré, durante e pós ditadura militar.

Nesta mesma linha de análise histórica, Sandoval e Nuñez (2013) fazem uma reflexão sobre o processo vivido pela terapia ocupacional durante os câmbios políticos na realidade chilena. Primeiro, o período no qual o Estado trabalhava sob a perspectiva do Estado de Bem Estar Social, com grande inserção estatal nas políticas sociais, aumento no número de emprego e investimentos nas universidades. No período ditatorial e neoliberal, quando a profissão perdeu ofertas e campos de trabalho, sofreu modificações em sua grade curricular de formação graduada, com a retirada de disciplinas como sociologia e antropologia (Sandoval, Nuñez, 2013).

A perspectiva histórica da profissão e dos conceitos que a permeiam é trabalhada em muitos ensaios teóricos. O conceito de trabalho para a terapia ocupacional, por exemplo, é discutido em um estudo que aborda os pontos modificados pela terceira revolução industrial, como o sistema de produção, o emprego e o desemprego, os trabalhadores, a saúde, o tempo livre e sua relação com a prática do terapeuta ocupacional (Felizzola, 2003). A autora apresenta as modificações sofridas neste campo e afirma que as influências econômicas, sociais e culturais alteraram os padrões de abordagem da terapia ocupacional no que se refere à prática profissional.

Os conceitos de ocupação e atividade, segundo Alvarez e colaboradores (2007), também sofreram transformações ao longo dos anos. Os autores trabalham com a perspectiva histórica da terapia ocupacional chilena e novas formas de intervenção, para além da saúde. Apontam que o início da profissão no Chile se deu em meio a muitas mudanças sociais, o que levou a criação de equipes de saúde de viés comunitário. Em 1990, devido a reconfiguração mundial em torno da globalização, outros temas foram incorporados como desafios para os profissionais, tais como a pobreza, a realidade de pessoas em situação de rua, a integração de pessoas com deficiência à sociedade, a vida de pessoas com vírus HIV, entre outras situações. Neste momento, a terapia ocupacional começa a retomar paulatinamente a sua linguagem histórica, a qual fala da importância do fazer com sentido para toda pessoa, vinculado às suas crenças e vida dentro de um entorno social e cultural, respeitando suas escolhas e oferecendo formas de auxílio ao seu exercício da autonomia.

Em consonância ao período de transição indicado, dois artigos abordaram a perspectiva de um deslocamento de paradigma para a terapia ocupacional chilena. Morrison (2011) realiza um estudo com o objetivo de analisar os conteúdos e as formas de elementos retóricos aplicados à profissão, a fim de contribuir com a reflexão crítica sobre Terapia Ocupacional e Ciência da Ocupação. O autor analisa os discursos sobre terapia ocupacional apresentando uma perspectiva crítica da profissão: a produção de conhecimento, sua relação com a ciência e com a ação humana e social.

Morrison, Olivares e Vidal (2011) realizam uma discussão a respeito da construção de um novo paradigma para a Ciência da Ocupação e para a Terapia Ocupacional, denominando de Paradigma Social da Ocupação. Aborda as possibilidades de novas atuações do profissional, sendo elas a terapia ocupacional comunitária ou social. Na atualidade, o conceito de ocupação humana deve ser concebido não apenas como abrangente da dimensão individual, mas sim como um fenômeno social, segundo os autores, em um Paradigma Social da Ocupação. A ocupação é contextualizada como um fenômeno sistêmico, complexo, econômico, político, sanitário, cultural, social e coerente com a justiça e bem estar das comunidades, ampliando o conceito clássico em uso, que se fundamenta em uma tradição clínica e individual.

Os textos discutidos apontam consonância aos pressupostos da terapia ocupacional social brasileira, principalmente quanto à superação da visão individualizada, ahistórica e calcada na clínica biomédica. Observamos que a maioria dos textos que apresenta uma perspectiva histórica se refere a estudos recentes, especificamente publicados nos últimos cinco anos, o que nos permite inferir um movimento de reflexão e transição da profissão na região latino-americana, adentrando uma perspectiva coletiva e social para fundamentar a atuação terapêutico ocupacional.

Os dados apresentados são insuficientes para afirmar que a terapia ocupacional latino-americana está caminhando para uma prática social. Entretanto, o caminho histórico, a quebra de valores e os questionamentos frente à produção de conhecimento e práticas nos revelam uma similaridade nos processos vivenciados e certa congruência nas discussões e pensamentos formados. 


\section{Conclusão}

Caminhamos para uma terapia ocupacional alicerçada em pressupostos com base nas realidades sócio -históricas dos países do sul, da América Latina?

A terapia ocupacional social brasileira nasceu do confronto com a prática e caminhou para a produção teórica a partir das inquietações e questionamentos constantes. Caminho este que não foi findado, frente à luta, às novas produções e às constantes discussões para se constituir como uma área no interior da profissão, com metodologias, objetivos, espaços e populações específicos.

Vale assinalar que este desenvolvimento e a discussão aqui propostos não anulam a importância e a permanência de abordagens em saúde, clínicas e individuais no campo da terapia ocupacional. Pelo contrário, na valorização de sua relevância e aplicabilidade a determinados problemas, verificase sua insuficiência e a necessidade de expansão, incluindo novos setores de atuação, como a área social.

A proposta da pesquisa bibliográfica foi nos aproximarmos da produção latino-americana para conhecer como o caminho que tem sido trilhado na discussão em relação à área social. Observamos que os textos relatam e refletem sobre práticas profissionais que abriram espaços para as críticas e os questionamentos, gerando um importante desequilíbrio de valores.

As profissões se modelam conforme as realidades sociais, vivências e atores sociais que as compõem. Assim, nós, latino-americanos, temos que desenvolver metodologias de ação e aportes teóricos que sejam singulares à nossa realidade e se direcionem, efetivamente, a buscar respostas às demandas da nossa sociedade.

Frank Kronenberg, um dos autores de um importante compilado de trabalhos sobre novas formas de atuação na atualidade, nos afirma "tenemos que perder el norte para encontrar nuestra terapia ocupacional en el sur"6. Fazemos referência que a emergência da questão social para a América Latina nos move para um encontro para além do contexto social e das populações vulneráveis - com a terapia ocupacional latino-americana.

Propomos uma maior aproximação entre os países da região para possíveis trocas e consequentes ganhos; para alianças em discussões, saberes e pesquisas; e

6 Citação retirada de imagem disponível em: http://mcultural-hli. blogspot.com.br/. Acesso em: 10 abri 2015 para a construção de uma nova perspectiva profissional comprometida socialmente com nosso contexto.

\section{REFERÊNCIAS BIBLIOGRÁFICAS}

Alvarez, E., Gómez S., Muñoz, I,; Navarrete, E.; Riveros, M. E; Rueda, L. Salgado, P., Sepúlveda, R., Valdebenito, A. (2007) Definición y desarrollo del concepto de Ocupación: ensayo sobre la experiencia de construcción teórica desde una identidad local. Revista Chilena de Terapia Ocupacional, 7(1), 1-9. DOI: 10.5354/07175346.2007.81.

Aranda, C. F., Yupanki, A. C., Verdugo, W. H. (2014) Terapia ocupacional y andragogía. Un llamado a la inclusión desde el fin del mundo. Revista Chilena de Terapia Ocupacional, 14 (1), 142-150. DOI: 10.5354/0717-5346.2014.32399.

Arellano, V. M., Correa, S. S. (2008) Talleres de promoción de resiliencia para adolescentes en alto riesgo social. Revista Chilena de Terapia Ocupacional, 8(1), 1-15. DOI: 10.5354/0717-5346.2008.76.

Barros, D. D.; Ghirardi, M. I. G.; Lopes, R. E. (2002) Terapia ocupacional social. Revista de Terapia Ocupacional da Universidade de São Paulo, São Paulo, (13)2, 95-103. DOI: 10.11606/issn.2238-6149. v13i3p95-103.

Barros, D. D., Ghirardi, M. I. G. \& Lopes, R. E. (2007). Terapia ocupacional social: una perspectiva sociohistórica. In: F. Kronenberg, S. Simó Algado \& N. Pollard. (Eds.) Terapia ocupacional sin fronteras: aprendiendo del espíritu de supervivientes, (pp.141-153). Buenos Aires, Argentina: Madri, España: Médica Panamericana.

Barros, D. D.; Lopes, R.E.; Galhiego, S. M. (2002) Projeto Metuia: terapia ocupacional no campo social. In: O Mundo da Saúde, 26(3), 365-69.

Boggio R., C., Chiapessoni, D., Funes, J. C., Arenaza, M. D. V., Boffelli, M., Heit, M., Demichelis, M.,Demiryi, M. (2006) Informe de primera etapa del proyecto de investigación sobre el tema "La modificación de los hábitos y rutinas diarias de personas afectadas por la catástrofe hídrica de la ciudad de Santa Fe". Revista Chilena de Terapia Ocupacional, Santiago, (6)1. DOI: 10.5354/07175346.2006.109.

Brasil. (1990) Ministério da Saúde. Secretaria Nacional de Assistência à Saúde. ABC do SUS: doutrinas e princípios, Brasília, Imprensa Oficial.

Capozzo, M.; Gómez Mengelberg, E. (2006) Un enfoque sobre la medición y nuestra disciplina. Revista Chilena de Terapia Ocupacional, Santiago, (6)1, s/p. DOI: 10.5354/0717-5346.2006.107.

Castel, R. (1994) Da indigência à exclusão, a desfiliação. Precariedade do trabalho e vulnerabilidade relacional. In: Lancetti, A. (Org.). Saúde loucura (pp. 21-48) São Paulo: Hucitec.

Castel, R. (1998) As metamorfoses da questão social: uma crônica do salário. Petrópolis: Editora Vozes. 
Cavalcante, G. M. M., Tavares, M. M. F., Bezerra, W. C. (2008) Terapia Ocupacional e Capitalismo: articulação histórica e conexões para a compreensão da profissão. Revista de Terapia Ocupacional da Universidade de São Paulo. São Paulo, (19)1, 29-33. DOI: 10.11606/issn.2238-6149.v19i1p29-33.

Cifuentes, R., Molina, P., Moya, P., Palacios, M. (2014) La casa de los sueños: ocupación, actividad transgresora y construcción de identidad. Revista Chilena de Terapia Ocupacional, (14)2, 231-244. DOI: 10.5354/0717-5346.2014.35725.

Coffito, (2010) Conselho Federal de Fisioterapia e Terapia Ocupacional. Resolução n. 383/2010.

De Carlo, M. P., Bartalotti, C.C. (2001) Caminhos da Terapia Ocupacional. En De Carlo, M. P., Bartalotti, C.C. Terapia Ocupacional no Brasil: Fundamentos e Perspectivas (pp. 10-40) São Paulo. Plexus Editora.

Diáz, S. M, Encina, V. V., Sepúlveda, R., Gonzalo, G.C. (2008) OCUPARSE: Una propuesta de intervención con personas privadas de libertad basado en la ocupación. Revista Chilena de Terapia Ocupacional, 8(1), 1-12. DOI: 10.5354/0717-5346.2008.71.

Drápela, J. B., Huidobro, M. A. G., Núñez, J. S., Palacios, M. T. (2008). "Significados Asociados a la Actividad Delictiva". En hombres que se encuentran privados de libertad, por delito de robo, en Centro de Detención Preventiva Santiago Sur. Revista Chilena de Terapia Ocupacional, 8(1),1-15. DOI: 10.5354/0717-5346.2008.75.

Felizzola, O. L. P. (2003) Aproximación crítica a la terapia ocupacional en la era de la información. Revista Chilena de Terapia Ocupacional, 3(1), 1-13. DOI: 10.5354/0717-5346.2003.152.

Galeano, E. (1982) As veias abertas da América Latina. $2^{\text {a }}$ ed. Rio de Janeiro: Editora Paz e Terra.

Galheigo, S. M. (2003) O social: Idas e vindas de um campo de ação em terapia ocupacional. En Pádua, E. M. M., Magalhães, L. V. Terapia Ocupacional: Teoria e Prática. Campinas. Papirus.

Galheigo, S. M., Simó Algado, S. (2012) Maestras de la terapia ocupacional. Sandra Galhiego: la poderosa emergencia de la terapia ocupacional social. Revista de Terapia Ocupacional Galícia. 9(15), 1-41.

Galhiego, S. M. (2014) Sobre identidades, latinoamericanidades e construção de saberes em Terapia Ocupacional: diálogos com Boaventura de Sousa Santos. Cadernos de Terapia Ocupacional da UFSCar, São Carlos, 22(1), 215-221. DOI: 10.4322\%2Fcto.2014.023.

Lopes, R. E., Adorno, R. F. C., Malfitano, A. P. S., Takeiti, B. A., Silva, C. R., Borba, P. L. O. (2008) Juventude pobre, violência e cidadania. Saúde e Sociedade, São Paulo, 17(3), 63-76. DOI: 10.1590/S010412902008000300008

Lopes, R. E. Borba, P. L. O, Silva, C. R., Malfitano, A. P. S. (2012) Terapia Ocupacional no campo social no Brasil e na América Latina: panorama, tensões e reflexões a partir de práticas profissionais. Cadernos de Terapia Ocupacional da UFSCar, São Carlos, 20(1), 21-32. DOI: 10.4322/cto.2012.003.
Lopes, R.E., Malfitano, A. P. S., Silva, C.R., Borba, P.O.L. (2015) Historia, conceptos y propuestas en la Terapia Ocupacional Social de Brasil. Revista Chilena de Terapia Ocupacional, Santiago, 15(1), 73-84. DOI: 10.5354/0717-5346.2015.37132.

Medeiros, M. H. R. (2003) Terapia Ocupacional: um enfoque epistemológico e social. São Carlos. EdUFSCar.

Moreno, A. F. (2012) Publicaciones seriadas de la terapia ocupacional en latinoamerica. Cadernos de Terapia Ocupacional da UFSCar, São Carlos, 20(2), 287-292. DOI: 10.4322/cto.2012.029.

Morrison J., R. (2011) La retórica de la ciencia. Descripciones y reflexión crítica respecto a la conformación del conocimiento. Revista Chilena de Terapia Ocupacional, Santiago, 11(1), 1-13. DOI: 10.5354/0717-5346.2011.17085.

Morrison J., R., Olivares A., D., Vidal M., D. (2011) La Filosofía de la Ocupación Humana y el Paradigma Social de la Ocupación. Algunas reflexiones y propuestas sobre epistemologías actuales en Terapia Ocupacional y Ciencias de la Ocupación. Revista Chilena de Terapia Ocupacional, Santiago, 11(1), 112-119. DOI: 10.5354/07175346.2011.17785.

Muñoz B., D.; Pinto V., R.; Rosas L., V.; Sánchez G., M.; Sánchez Z., S. (2014) La contribución de la ocupación en la construcción de la cultura en la feria libre de la comuna de Valdivia. Revista Chilena de Terapia Ocupacional, Santiago, 14(1), 63-72. DOI: 10.5354/0717-5346.2014.32389.

Muñoz Espinosa, I. (2007) La formación de terapeutas ocupacionales desde un interés crítico de la Educación. Revista Chilena de Terapia Ocupacional, Santiago, 7(1), 1-9. DOI: 10.5354/07175346.2007.80.

Navarrete Salas, E. et al. Terapia Ocupacional y Exclusión Social: Hacia una praxis basada en los derechos humanos. Santiago: Editorial Segismundo Spa, 2015.

Oyarzun S., N., Zolezzi G., R., Núñez S., J., Palacios T., M. (2009) Hacia la construcción de las prácticas comunitárias de terapeutas ocupacionais em Chile, desde uma mirada sócio histórica, desde 1972 hasta la actualidad. Revista Chilena de Terapia Ocupacional, Santiago, 9(1), 149-165. DOI: 10.5354/0717-5346.2009.120.

Pan, L. C.; Lopes, R. E. (2013) O ensino de terapia ocupacional social nas universidades públicas do Estado de São Paulo. Revista de Terapia Ocupacional da USP, São Paulo, 24(2), 103-11. DOI: 10.11606/ issn.2238-6149.v24i2p103-111

Poblete A., M. J. (2014) Identificación delictual juvenil: una propuesta de intervención ocupacional. Revista Chilena de Terapia Ocupacional, 14(1), 45-52. DOI: 10.5354/0717-5346.2014.32387.

Ramírez P., R.; Schliebener T., M. (2009) Ocupación y literatura, un análisis desde la dialéctica materialista. Revista Chilena de Terapia Ocupacional, 9(1), 1-16. DOI: 10.5354/0717-5346.2009.121

Reis, T. A. M. (2008) A Terapia Ocupacional Social: análise da produção científica no estado de São Paulo. (Tese inédita de mestrado) Faculdade de Medicina. Universidade de São Paulo. São Paulo, Brasil. 
Reis, T. A. M. R., Barros, D. D., Uchidomari, I. Y. (2010) A terapia ocupacional social nos congressos brasileiros (1997-2007): desafios e debates de um campo emergente. Revista de Terapia Ocupacional da Universidade de São Paulo, São Paulo, 21(2), 111-120. DOI: 10.11606/issn.2238-6149.v21i2p111-120

Sandoval, M. H., Núñez, C. V. (2013) Gubernamentalidad y biopolítica: una aproximación con los saberes y prácticas históricas de la terapia ocupacional en Chile. Revista Chilena de Terapia Ocupacional, Santiago, 13(2), 79-92. DOI: 10.5354/0717-5346.2013.30218.

Soares, L. B. T. (1991) Terapia Ocupacional: Lógica do Capital ou do Trabalho. São Paulo. Hucitec.

Testa, D. (2012) Aportes para el debate sobre los inicios de la profesionalización de la terapia ocupacional em Argentina. Revista Chilena de Terapia Ocupacional, Santiago, 12(1), 67-78. DOI: 10.5354/0717-5346.2012.22054.

Valderrama Nuñez, C. (2013) Acercamientos teorico-éticos sobre la relación entre la terapia ocupacional y la ciencia: implicancias en las prácticas disciplinares. Revista Chilena de Terapia Ocupacional, Santiago, 13(1), 11-21. DOI: 10.5354/0717-5346.2013.27448.

Yasui, S. (2006) Rupturas e encontros: desafios da Reforma Psiquiátrica Brasileira. (Tese inédita de doutorado) Escola Nacional de Saúde Pública da Fundação Oswaldo Cruz. Rio de Janeiro, Brasil. 